\title{
Application of a Chemometric Method to Interpret Spectrophotometric Data Obtained for Degradation of an Organic Dye in Water Using Manganese Oxide
}

\author{
Thaís A. Cosendey, ${ }^{a}$ Antônio A. Neves, ${ }^{(\oplus *, a}$ Liany D. L. Miranda, ${ }^{a}$ \\ Maria E. L. R. de Queiroz, ${ }^{\circledR a}$ André F. de Oliveira, ${ }^{\circledR a}$ Efraim L. Reis ${ }^{a}$ and \\ Wesley L. Gabriel ${ }^{a}$
}

${ }^{a}$ Departamento de Química, Universidade Federal de Viçosa, 36570-900 Viçosa-MG, Brazil

\begin{abstract}
Birnessite type manganese oxide $\left(\delta-\mathrm{MnO}_{2}\right)$ was synthesized for use in degradation of the cationic dye methylene blue in aqueous solution. The material was characterized using infrared spectroscopy, X-ray diffraction, and Brunauer-Emmett-Teller (BET) surface area calculations. The removal of the dye from aqueous solutions was evaluated considering the effects of the following variables: $\mathrm{pH}$, manganese oxide concentration, contact time, and temperature. UV-Vis spectroscopy analyses indicated achievement of 99 and $95 \%$ removal of methylene blue $\left(7 \mathrm{mg} \mathrm{L}^{-1}\right)$ at $\mathrm{pH} 2.0$ and 4.0, respectively, after $120 \mathrm{~min}$ of contact with the birnessite $\left(100 \mathrm{mg} \mathrm{L}^{-1}\right)$. At higher $\mathrm{pH}$ of 6.0 and 8.0, removals of around 99 and $80 \%$, respectively, were obtained after a longer time of $1860 \mathrm{~min}$. Analyses of total organic carbon (TOC) revealed that $80 \%$ reduction of organic matter was obtained at $\mathrm{pH}$ 4.0. The method of multivariate curve resolution-alternating least squares (MCR-ALS) was used together with UV-Vis spectroscopy to evaluate the removal process, confirming the degradation of methylene blue. Thionine $\left(\lambda_{\max }=601 \mathrm{~nm}\right)$ was identified as one of the byproducts of $N$-demethylation of methylene blue. The results indicated that the degradation process started with $\mathrm{N}$-demethylations of the methylene blue molecule.
\end{abstract}

Keywords: birnessite, methylene blue, degradation

\section{Introduction}

The chemistry of manganese is complex due to its various oxidation states (II, III, IV, VI, and VII), resulting in the formation of a range of oxides with different morphologies, porosities, and textures..$^{1-4}$ One of these oxides, birnessite, has attracted attention because of its suitability for use in adsorption and catalysis. ${ }^{5}$

The structure of birnessite consists of layers of $\mathrm{MnO}_{6}$ octahedrons that share vertices and edges. $\mathrm{Mn}^{\mathrm{IV}}$ is the main form present in the lamellar structure of birnessite, together with small amounts of $\mathrm{Mn}^{\text {IIII. }} .{ }^{6-8}$ Alkali metal cations and water molecules are present between the oxide layers. The compounds are mesoporous and/ or macropores, favoring adsorptive and ion exchange processes. ${ }^{5,9}$ They can also be chemically active, due to electron transfer arising from the reduction of $\mathrm{Mn}^{\mathrm{IV}}$ present in the structure. ${ }^{7,8,10,11}$

Several studies have reported the capacities of these oxides to remove organic molecules from water, including

*e-mail: aneves@ufv.br dyes, ${ }^{5,9,10}$ environmental contaminants such as bisphenol, ${ }^{12}$ and some beta-blockers. ${ }^{11}$

Dyes are considered important water pollutants as they can be toxic to microorganisms and harm aquatic life, while some synthetic dyes may be carcinogenic, mutagenic, and difficult to degrade. The complexity of the structures of these compounds increases their stability towards light and makes them resistant to biodegradation. ${ }^{13-16}$

The use of UV-Vis spectroscopy applied to processes of degradation and removal of dyes present in water can provide information about new compounds formed during these procedures. However, the spectral bands obtained are related to chromophores whose absorptions may be similar for different molecules, so signal overlap can make it impossible to distinguish between bands. ${ }^{17}$

The statistical method of multivariate curve resolutionalternating least squares (MCR-ALS) has attracted attention due to its ability to extract and recover overlapping information provided by UV-Vis spectroscopy, reducing the number of experiments required and consequently decreasing the amounts of reagents, solvents, and toxic residues. ${ }^{18-21}$ 
The objective of this work was to evaluate the use of birnessite to remove (by degradation or adsorption) methylene blue (MB) dye, as a model compound, from aqueous solutions. The process variables investigated were the concentrations of birnessite and $\mathrm{MB}$, contact time, temperature, and $\mathrm{pH}$ of the dye solution. Simple, fast, and selective monitoring of the process was achieved by combining the information obtained by UV-Vis spectroscopy with analysis of the results using the MCR-ALS chemometric method. This approach has not previously been reported in studies of the removal of organic species from aqueous systems.

\section{Experimental}

\section{Standards and reagents}

All solutions were prepared using analytical grade reagents, without further purification: hydroxylamine hydrochloride and sodium chloride were obtained from Isofar (Rio de Janeiro, Brazil). Potassium permanganate and tert-butyl alcohol were obtained from Vetec (Rio de Janeiro, Brazil). Ethyl alcohol and sodium nitrite were obtained, respectively, from Ls Chemicals and Dinâmica (São Paulo, Brazil). $1 \mathrm{~mol} \mathrm{~L}^{-1} \mathrm{HCl}$ and $\mathrm{NaOH}$ solutions both from Aldrich (St. Louis, USA) were used for $\mathrm{pH}$ adjustment. The dyes used were methylene blue, CAS: 61-73-4, obtained from Vetec (Rio de Janeiro, Brazil) and thionine acetate, CAS: 78338-22, from Aldrich (St. Louis, USA). The thionine acetate was used as a standard for the byproduct produced during degradation of MB by the manganese oxide.

\section{Synthesis of birnessite type manganese oxide}

The birnessite was prepared by the reduction of potassium permanganate using a solution of hydroxylamine hydrochloride, according to the method described by Liu et al. ${ }^{22}$ For this, a $200 \mathrm{~mL}$ volume of $0.07 \mathrm{~mol} \mathrm{~L}^{-1}$ $\mathrm{NH}_{2} \mathrm{OH} . \mathrm{HCl}$ solution was added dropwise (at a rate of ca. $0.7 \mathrm{~mL} \mathrm{~min}^{-1}$ ) to $200 \mathrm{~mL}$ of $0.1 \mathrm{~mol} \mathrm{~L}^{-1} \mathrm{KMnO}_{4}$ solution, with vigorous stirring. The addition of $\mathrm{NH}_{2} \mathrm{OH}$. $\mathrm{HCl}$ resulted in formation of a black-brown suspension, which was rapidly filtered and washed with deionized water until the conductivity of the filtrate was below $20.0 \mu \mathrm{S} \mathrm{cm}^{-1}$. The synthesized solid was dried in an oven, at $50{ }^{\circ} \mathrm{C}$ for $18 \mathrm{~h}$, followed by disaggregation in an agate mortar.

\section{Characterization of the synthetic birnessite}

The crystalline structure of the birnessite was characterized by X-ray diffraction (XRD), using a D8
DISCOVER instrument (Bruker) operating with $\mathrm{Cu} \mathrm{K} \alpha$ radiation $(\lambda=0.154 \mathrm{~nm})$, at $40 \mathrm{kV}$ and $40 \mathrm{~mA}$. The solid was analyzed by infrared spectroscopy-attenuated total reflectance (IR-ATR), using a Varian 660-IR instrument fitted with a GladiATR attenuated reflectance accessory (PIKE Technologies). The specific surface area was calculated according to the Brunauer-Emmett-Teller (BET) method, using data acquired from a surface analyzer (Quantachrome) operated with $0.077 \mathrm{~g}$ of sample and nitrogen adsorption/desorption at $77.3 \mathrm{~K}$.

Removal of methylene blue from aqueous systems using birnessite

The experiments to evaluate the influence of the different variables (contact time, birnessite loading, temperature, and solution $\mathrm{pH}$ ) were performed using a $1000 \mathrm{~mL}$ glass beaker as the reactor. Birnessite $\left(100 \mathrm{mg} \mathrm{L}^{-1}\right)$ was added to $500 \mathrm{~mL}$ of $7 \mathrm{mg} \mathrm{L}^{-1} \mathrm{MB}$ solution, at controlled temperature and $\mathrm{pH}$ (FiveEasy Plus pH meter, Mettler Toledo), with the mixture being gently agitated using a magnetic stirrer.

In sequence the solids were removed from the solution and submitted to desorptive procedures adding $9 \mathrm{~mL}$ of ethanol 99\% and using ultrasonic agitation (Sanders Medical, SoniClean 2, $40 \mathrm{kHz}$ ) for $40 \mathrm{~min}$.

\section{Chemometric analysis}

The MCR-ALS method was applied to the data in order to extract and recover possible overlapping information in the UV-Vis spectra, hence enabling the pure spectrum of each of the possible intermediaries in the dye degradation process to be obtained. An experimental matrix $\mathbf{D}$ is decomposed into two matrices $\mathbf{C}$ and $\mathbf{S}^{\mathrm{T}}$ that contains pure profiles of components, usually concentrations and spectra, respectively. The bilinear model is described by the equation, $\mathbf{D}=\mathbf{C} \times \mathbf{S}^{\mathbf{T}}+\mathbf{E}$, where $\mathbf{E}$ is the residual matrix that is not explained by the model. The iterative resolution of the equation above is performed with the algorithm ALS. The number of components is estimated using the singular value decomposition algorithm (SVD). ${ }^{21,23}$ Initial estimates in MCR-ALS can be concentration profiles or spectra. They can be obtained from previous knowledge about the system if available, such as the pure spectra of some of the components in the system. In case that there is no previous knowledge, there are methods that can help in the task of obtaining this initial information. A common denomination of these methods is pure variable selection methods. Some of the most widely known in the simple-touse self-modeling analysis also called SIMPLISMA, which selects the most dissimilar rows or columns in a single 
matrix or a multiset structure providing initial estimates of spectra or concentration profiles..$^{21,23}$

The spectral data for the aliquots of MB solution obtained in the $\mathrm{pH} 2,4,6$ and 8 were organized in single matrices and the MCR-ALS was applied to each set, the data were pre-processed using centering in all calculations. The number of components were estimated using the algorithm SVD and for initial estimates of spectra the SIMPLISMA were used. The maximum permitted noise of the spectrum was set at $0.01 \%$. Non-negativity restrictions were applied to the spectra and the concentrations.

The data treatment was performed in MATLAB v. $9.0^{24}$ using MCR-ALS GUI 2.0.25

\section{Results and Discussion}

\section{Characterization of the manganese oxide}

The synthesized manganese oxide was characterized by XRD, nitrogen adsorption/desorption at $77 \mathrm{~K}$, and IR-ATR. The surface area was calculated by method BET.

The XRD pattern was characteristic of amorphous birnessite type manganese oxide. ${ }^{22}$ Diffraction peaks appeared at around 7.52, 3.67, 2.44, and $1.41 \AA$. The first peak was related to the interplanar spacing. ${ }^{5,22,26-30}$ The broad and low intensity peaks could be explained by the synthesis method employed, ${ }^{22}$ since they were characteristic of the formation of small particles due to the rapid reaction of $\mathrm{NH}_{2} \mathrm{OH}$ with $\mathrm{KMnO}_{4}$ (Figure S1, Supplementary Information (SI) section).

The IR-ATR spectrum showed a band at $3303 \mathrm{~cm}^{-1}$, which could be attributed to stretching vibration of the $-\mathrm{OH}$ group of water molecules. A band at $1630 \mathrm{~cm}^{-1}$ was assigned to stretching vibration of adsorbed water. While in the region from 400 to $800 \mathrm{~cm}^{-1}$ stretching vibrations of the $\mathrm{Mn}-\mathrm{O}$ bonds ocurred (Figure S2, SI section). ${ }^{30,31}$

A surface area of $154.44 \mathrm{~m}^{2} \mathrm{~g}^{-1}$ was calculated using the BET method. This was close to the value of $142.1 \mathrm{~m}^{2} \mathrm{~g}^{-1}$ and was within the range 19-156 $\mathrm{m}^{2} \mathrm{~g}^{-1}$ reported for synthesized manganese oxides. ${ }^{22,28,32}$

Removal of methylene blue from aqueous systems using manganese oxide

\section{Effect of $\mathrm{pH}$}

The solution $\mathrm{pH}$ may affect the rate of oxidation of organic compounds by manganese oxides, due to protonation/deprotonation of the surface and changes in the stability of the crystalline lattice..$^{33}$ Therefore, a detailed study of the removal of MB using birnessite was performed with variation of the initial $\mathrm{pH}$ of the dye solution ( $\mathrm{pH}$ 2.0, 4.0, 6.0, and 8.0). The discoloration of the solution was monitored by observing the changes in the MB absorbance spectrum, considering the maximum absorbance wavelength $\left(\lambda_{\max }\right)$ peaks at 664 and $617 \mathrm{~nm}$. The results are shown in Figure 1.

The spectral changes observed during contact of MB with the birnessite showed that the dye was removed (Figure 1). The decreases of absorbance intensity at 644 and $270 \mathrm{~nm}$ were most pronounced at $\mathrm{pH} 2$ and 4 (Figures 1a and $1 \mathrm{~b}$ ). The band at $644 \mathrm{~nm}$ shifted to a lower wavelength $(617 \mathrm{~nm})$, while a broad band appeared at $450 \mathrm{~nm}$, which disappeared as the contact time increased. These changes suggested that the removal of MB was mainly due to degradation of the dye molecule, with the formation of intermediary compounds.

Previous studies also showed that in cationic dye removal processes performed using pyrolusite, ${ }^{34}$ glass fiber materials impregnated with birnessite, ${ }^{28}$ and pure birnessite, ${ }^{10}$ there were shifts of the spectral bands, with higher removal efficiencies achieved under more acidic conditions.

The rate of removal/degradation of MB was determined using the absorbance at $664 \mathrm{~nm}$. Therefore, aliquots were periodically removed from the system, filtered $(0.45 \mu \mathrm{m}$ filter), and subsequently analyzed by UV-Vis spectroscopy in the wavelength range 200-700 $\mathrm{nm}$ (model U-2000, Hitachi). according to equation 1 :

$\operatorname{Removal}(\%)=\frac{A_{i}-A_{t}}{A_{i}} \times 100$

where $A_{i}$ and $A_{t}$ are the absorbance values at the wavelength of maximum absorbance by MB $(664 \mathrm{~nm})$, at the initial time and at each time interval, respectively.

The spectra obtained at $\mathrm{pH} 2.0$ (Figure 1a) showed that after $120 \mathrm{~min}$, the absorbances were close to zero throughout the spectrum $(230-700 \mathrm{~nm})$, with an average decrease of $99 \%$. At pH 4.0 (Figure 1b), the process was similar, but slower, with $95 \%$ of the absorbance removed after $120 \mathrm{~min}$, as shown by the non-zero absorbance values in the region between 450 and $650 \mathrm{~nm}$.

The degradation process was slower at higher $\mathrm{pH}$ (Figures 1c and 1d). At pH 6.0 (Figure 1c), the absorbance at $664 \mathrm{~nm}$ only decreased by $99 \%$ after around $22 \mathrm{~h}$ (1320 min), while a wavelength shift was observed for the peak at $601 \mathrm{~nm}$. These features were similar to the findings by other authors. ${ }^{28,34}$

At $\mathrm{pH} 8.0$ (Figure 1d), the decay of the maximum absorbance band at $664 \mathrm{~nm}$ was even slower, with incomplete removal of the absorbance after $31 \mathrm{~h}(1860 \mathrm{~min})$ of reaction.

These results suggested that at lower $\mathrm{pH}$, the removal 

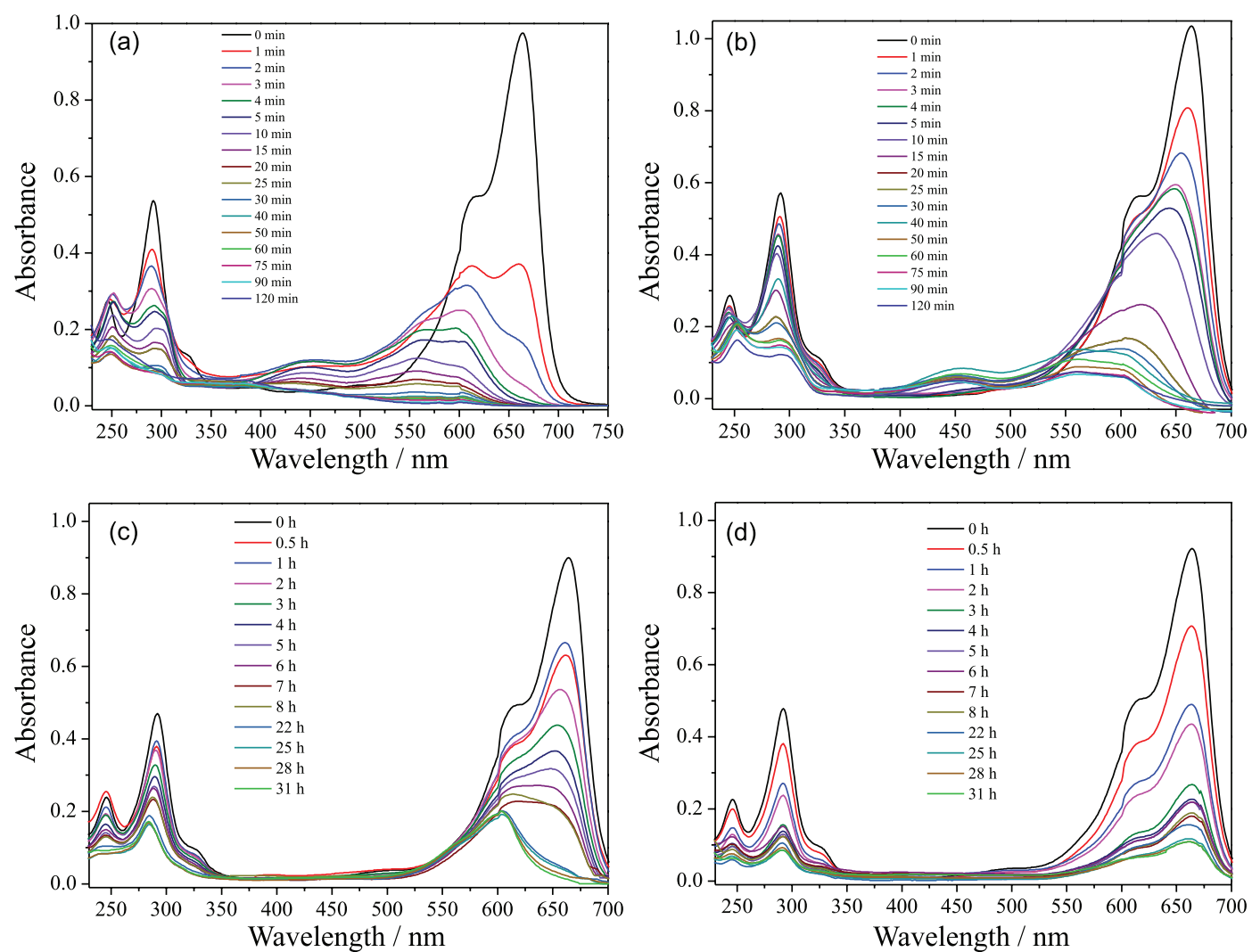

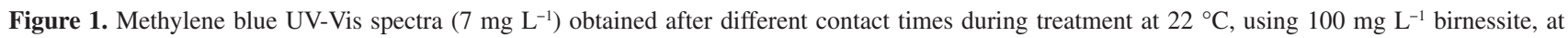
different solution pH values: (a) 2.0; (b) 4.0; (c) 6.0; (d) 8.0.

of MB was due to stepwise degradation of the compound, with the formation of intermediaries that were also removed during the process. At higher $\mathrm{pH}$, there was a decrease of absorption intensity at all wavelengths, with the removal of color probably being associated with the formation of a colorless final product and/or a small number of intermediaries with overlapping absorption bands.

In order to evaluate whether the MB removal process was related to electrostatic attraction between the birnessite surface and the cationic dye, the $\mathrm{pH}_{\mathrm{pzc}}$ (point of zero charge $\mathrm{pH}$ ) of the oxide was determined (Figure S3, SI section). ${ }^{32}$ The $\mathrm{pH}_{\mathrm{pzc}}$ was 6.22 , so at values below this $\mathrm{pH}$, the surface of the oxide would present mainly positive charges, hence favoring the attraction of anionic compounds. Nonetheless, as in the present work, other studies ${ }^{7,10,28,33,34}$ have also observed the removal of cationic dyes even at very low $\mathrm{pH}$.

The stability of the layered crystalline structure of birnessite is weaker at low $\mathrm{pH}$, because the reduction of $\mathrm{Mn}^{\mathrm{IV}}$ present in the birnessite structure is favored (equation 2). ${ }^{1,35}$ Under such conditions, redox reactions are facilitated by the direct transfer of electrons between the surface and the organic compound, with the reduction of $\mathrm{Mn}^{\mathrm{IV}}$ to $\mathrm{Mn}^{\mathrm{II}}$.

$$
\begin{aligned}
& \mathrm{Mn}^{\mathrm{III/N}} \mathrm{O}_{1.8(\mathrm{~s})}+3.6 \mathrm{H}_{(\text {aq })}^{+}+1.6 \mathrm{e}^{-} \rightleftharpoons \mathrm{Mn}_{(\text {aq })}^{2+}+1.8 \mathrm{H}_{2} \mathrm{O}_{(1)}, \\
& \mathrm{E}_{0}=+1.23 \mathrm{~V}
\end{aligned}
$$

Different reaction mechanisms have been proposed to describe the process of degradation of organic compounds by birnessite. The oxidative degradation of MB occurs according to a surface mechanism, with the organic compound being adsorbed on the surface of the Mn oxide, followed by rapid formation of a surface complex. ${ }^{7}$ The subsequent transfer of electrons from the organic reductant results in the reduction of $\mathrm{Mn}^{\mathrm{IV}}$ to $\mathrm{Mn}^{\mathrm{II}}$. This is followed by $\mathrm{N}$-demethylation processes in which the loss of methyl groups leads to intermediary compounds such as azure $\mathrm{B}$, azure $\mathrm{A}$, azure $\mathrm{C}$, and thionine, which present absorption bands at around 638, 628, 618, and $601 \mathrm{~nm}$, respectively. The thionine is adsorbed on the surface of birnessite, with its subsequent mineralization proceeding very slowly. ${ }^{7}$

Differently, other authors ${ }^{15}$ proposed a degradation mechanism based on the generation of hydroxyl radicals $\left({ }^{\circ} \mathrm{OH}\right)$ during the conversion of $\mathrm{Mn}^{\mathrm{IV}}$ to $\mathrm{Mn}^{\mathrm{II}}$ (equation 3). These radicals could then degrade organic compounds, with the formation of inorganic products.

$$
\begin{aligned}
& \mathrm{Mn}^{\mathrm{IV}} \mathrm{O}_{2(\mathrm{~s})}+2 \mathrm{H}^{+}{ }_{(\mathrm{aq})}+2 \mathrm{e}^{-} \rightleftharpoons \mathrm{Mn}^{2+}{ }_{(\mathrm{aq})}+2 \mathrm{OH}_{(\mathrm{aq})}, \\
& \mathrm{E}_{0}=+1.23 \mathrm{~V}
\end{aligned}
$$

The overall process can be described as being a combination of several sequential steps: 
(i) Formation of the precursor complex:

$$
1 / 2 \mathrm{Mn}^{\mathrm{IV}}+2 \mathrm{HOH} \rightleftharpoons\left(1 / 2 \mathrm{Mn}^{\mathrm{IV}}, 2 \mathrm{HOH}\right)
$$

(ii) electron transfer:

$$
\left(1 / 2 \mathrm{Mn}^{\mathrm{IV}}, 2 \mathrm{HOH}\right) \rightleftharpoons\left(1 / 2 \mathrm{Mn}^{\mathrm{II}}, 2 \cdot \mathrm{OH}\right)+2 \mathrm{H}^{+}
$$

(iii) hydroxyl radical release:

$$
\left(1 / 2 \mathrm{Mn}^{\mathrm{II}}, 2 \cdot \mathrm{OH}\right) \rightleftharpoons 1 / 2 \mathrm{Mn}^{\mathrm{II}}+2 \cdot \mathrm{OH}
$$

(iv) release of reduced $\mathrm{Mn}$ :

$$
1 / 2 \mathrm{Mn}^{\mathrm{II}} \rightleftharpoons 1 / 2 \mathrm{Mn}^{2+}
$$

In order to elucidate the mechanism of degradation of MB by birnessite, the degradation process was monitored by UV-Vis spectroscopy, with the data obtained being treated using the MCR-ALS chemometric method. For this, matrices of the absorbance data obtained at $\mathrm{pH} 2.0,4.0,6.0$, and 8.0 were imported into MATLAB v. 9.0. ${ }^{24}$

The resolution achieved by MCR-ALS enables the separation and identification of compounds in multicomponent mixtures such as those resulting from catalysis. ${ }^{21,36,37}$ Figures 2a-2d show the absorbance spectra and the corresponding relative concentrations, as a function of the time of contact between $\mathrm{MB}$ and the birnessite at the different $\mathrm{pH}$ values, for the purest components obtained by the algorithm.

For $\mathrm{pH} 2.0$ (Figure 2a), decomposition of the singular values enabled the recovery of four different purer spectra from the data matrix, including the MB and thionine (Th) spectra, as well as two spectra of byproducts denoted SUB.A and SUB.B. Thionine was the final byproduct of the $\mathrm{N}$-demethylations of $\mathrm{MB},{ }^{7}$ although the degradation continued, forming the compound SUB.B, which was the last byproduct presenting maximum absorption in the ultraviolet region.

For $\mathrm{pH} 4.0$ (Figure $2 \mathrm{~b}$ ), four different purer spectra were recovered from the data matrix, including the spectra of MB, SUB.A, and Th. The profile of the spectrum denoted SUB.C differed from the profiles of the spectra recovered at $\mathrm{pH} 2.0$, possibly due to the slower degradation kinetics at $\mathrm{pH} 4.0$, which could have facilitated the recovery of this byproduct spectrum.

Since the degradation process was slower at $\mathrm{pH} 4.0$, the contact time of 120 min was insufficient for completion of the $N$-demethylation reactions and arrival at byproduct SUB.B. Therefore, experiments were performed using a longer contact time and will be shown later.
For pH 6.0 (Figure 2c), there was recovery of the pure spectrum of a different byproduct (SUB.D), together with the MB and Th spectra. For pH 8.0 (Figure 2d), only the $\mathrm{MB}$ and Th spectra were recovered.

For all the $\mathrm{pH}$ values studied, the quality parameters obtained in the MCR-ALS, in terms of the lack of fit (LOF), were in the range from 3.77 to $6.83 \%$, while the percent explained variance values $\left(\mathrm{R}^{2}\right)$ exceeded $99.55 \%$, indicating satisfactory estimation of the spectral profiles and concentrations. ${ }^{23,38}$

The thionine is expected to be the final byproduct of the $N$-demethylations of MB. ${ }^{7}$ Comparison between the MCR-ALS spectra with maximum absorption at $601 \mathrm{~nm}$ and the spectrum for a thionine standard (Figure 3), at the different $\mathrm{pH}$ values, revealed that the spectra were similar, evidencing the formation of thionine as a byproduct of MB degradation by the birnessite. Also, a comparison for the pure spectra recovered for MB by MCR-ALS and MB standard were performed (Figure 3), demonstrating that the MCR-ALS method can explain the variance of the data with high accuracy mathematically.

\section{Use of a longer contact time}

In order to confirm the similarity between the degradation mechanisms under conditions of low $\mathrm{pH}$ (2.0 and 4.0), the duration of contact between the birnessite and the MB (at $\mathrm{pH} 4.0$ ) was increased, in order to determine whether this would allow the degradation process to continue, with completion of the $N$-demethylations and the formation of SUB.B, as observed at $\mathrm{pH}$ 2.0.

Figure 4a shows the UV-Vis spectra obtained up to $60 \mathrm{~h}$ (3600 min) of reaction. It can be seen that the degradation was progressive and that at $60 \mathrm{~h}$ the absorbances were very close to zero throughout the wavelength range, with an average solution discoloration of $99 \%$. Figure $4 \mathrm{~b}$ shows the spectra generated using MCR-ALS, revealing the appearance of the SUB.B compound with maximum absorption in the ultraviolet region.

The increase of the contact time at this $\mathrm{pH}$ showed the importance of the $\mathrm{H}^{+}$protons for progression of degradation of the MB molecule to the byproduct with absorption in the ultraviolet region. The resolution of the MCR-ALS was satisfactory, with a low LOF value of $6.28 \%$, in relation to the original matrix, and percent explained variance $\left(\mathrm{R}^{2}\right)$ of $99.61 \%$.

\section{Determination of manganese in solution}

The concentrations of manganese ions in solution were determined during the degradation of $\mathrm{MB}\left(7 \mathrm{mg} \mathrm{L}^{-1}\right)$ by 
(a)
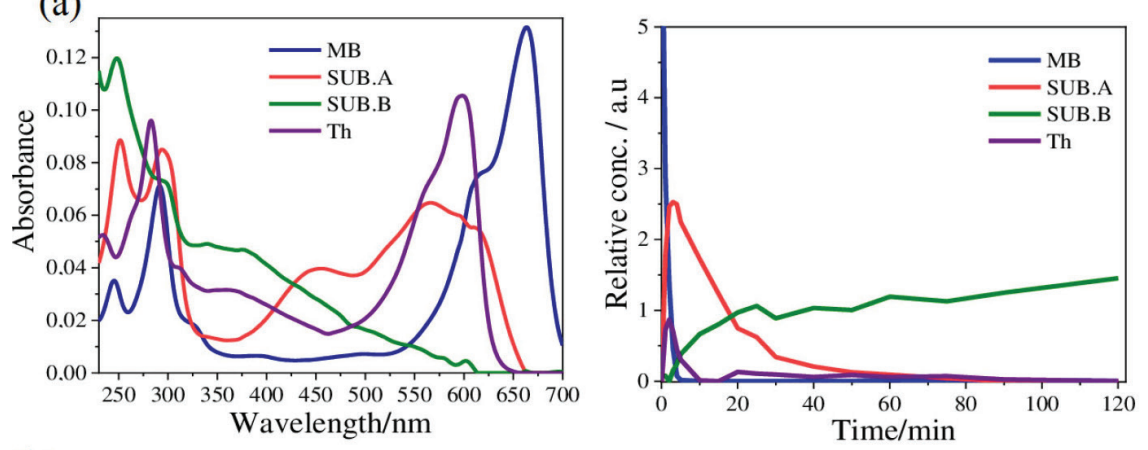

(b)
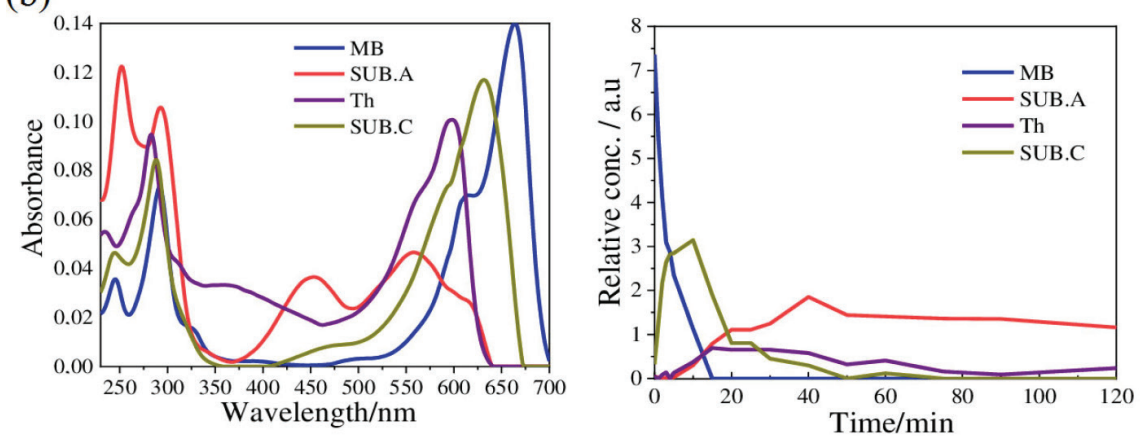

(c)

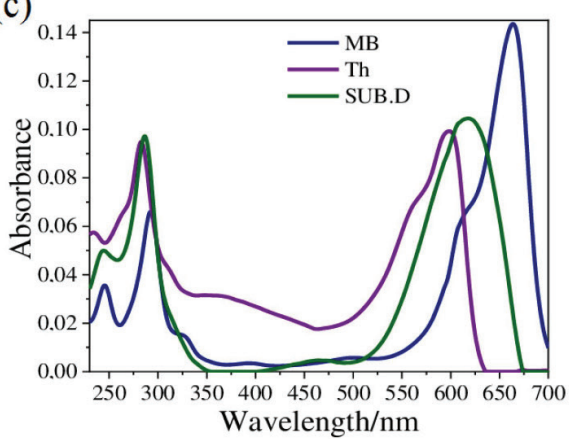

(d)

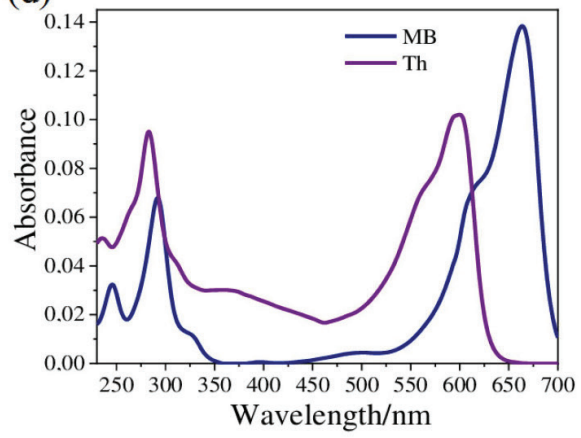

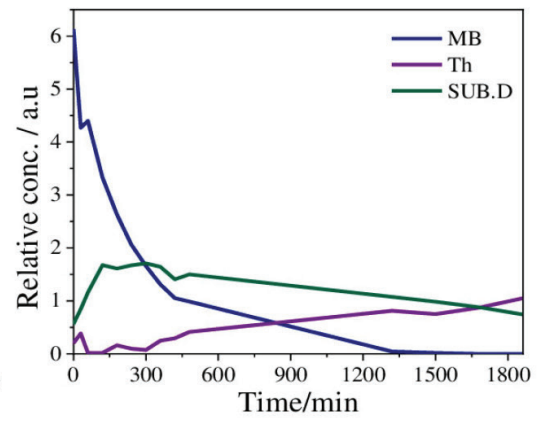

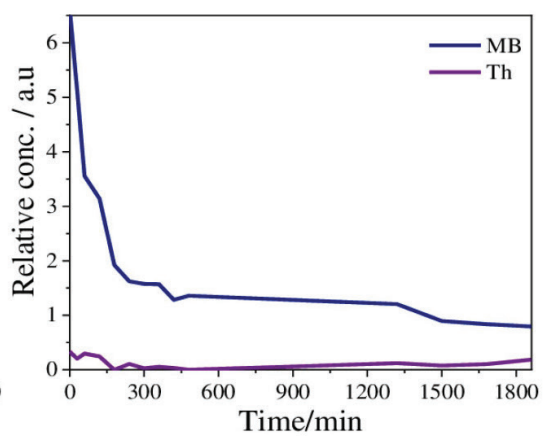

Figure 2. Spectra (left, absorbance versus wavelength) and relative concentrations (right, relative concentration as a function of contact time) of the purest components resolved by MCR-ALS, for the treatments at different pH: (a) 2.0; (b) 4.0; (b) 6.0; (d) 8.0.

the birnessite $\left(100 \mathrm{mg} \mathrm{L}^{-1}\right)$. Determination of Mn was also performed for an aqueous solution without the dye (blank). This experiment was performed similarly to the methodology described in "Removal of methylene blue from aqueous systems using birnessite" sub-section, but in the absence of the dye, with aliquots of the samples being filtered and analyzed by flame atomic absorption spectrometry (model $240 \mathrm{FS}$, Agilent Technologies), using an air:acetylene flame (13.50:2.0 $\left.\mathrm{L} \mathrm{min}^{-1}\right)$.

Birnessite has a small solubility in acidic aqueous solution ( $\mathrm{pH}$ 2) of approximately $3 \mathrm{mg} \mathrm{L}^{-1}$. This quantity remained in solution during the entire 120 min process (Figure 5). In the presence of $\mathrm{MB}$ at $\mathrm{pH} 2$, there was a progressive increase in the amount of manganese 
(a)

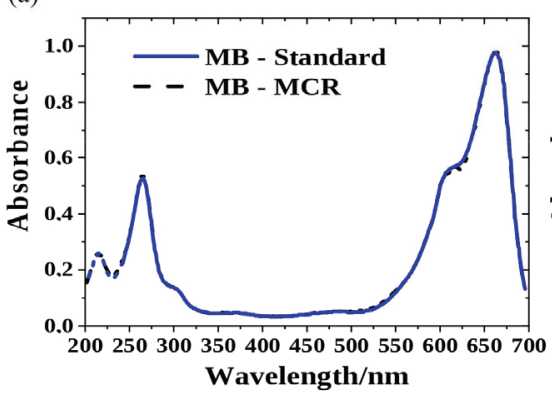

(b)

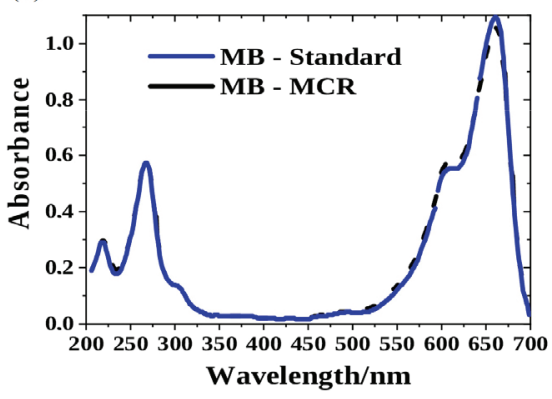

(c)

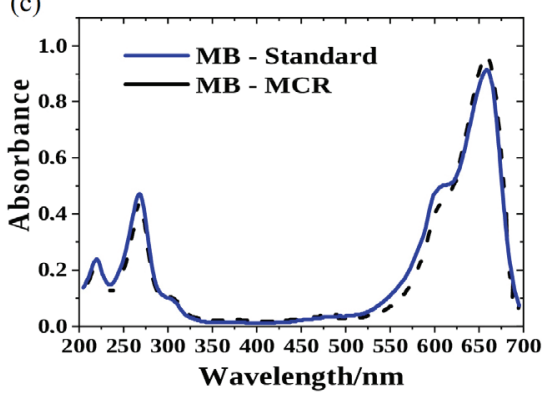

(d)

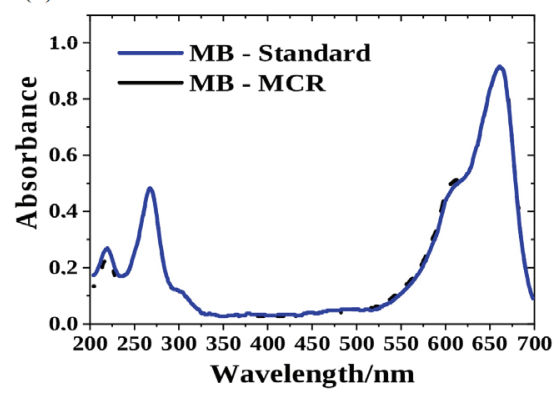

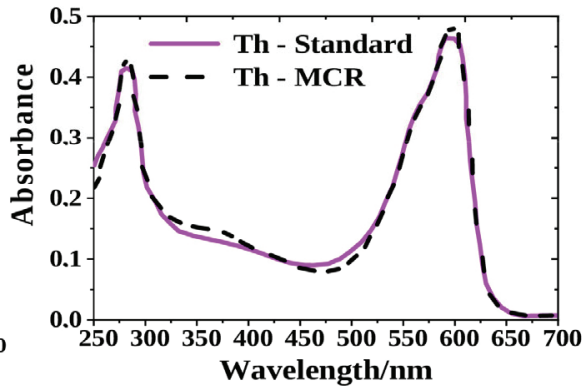
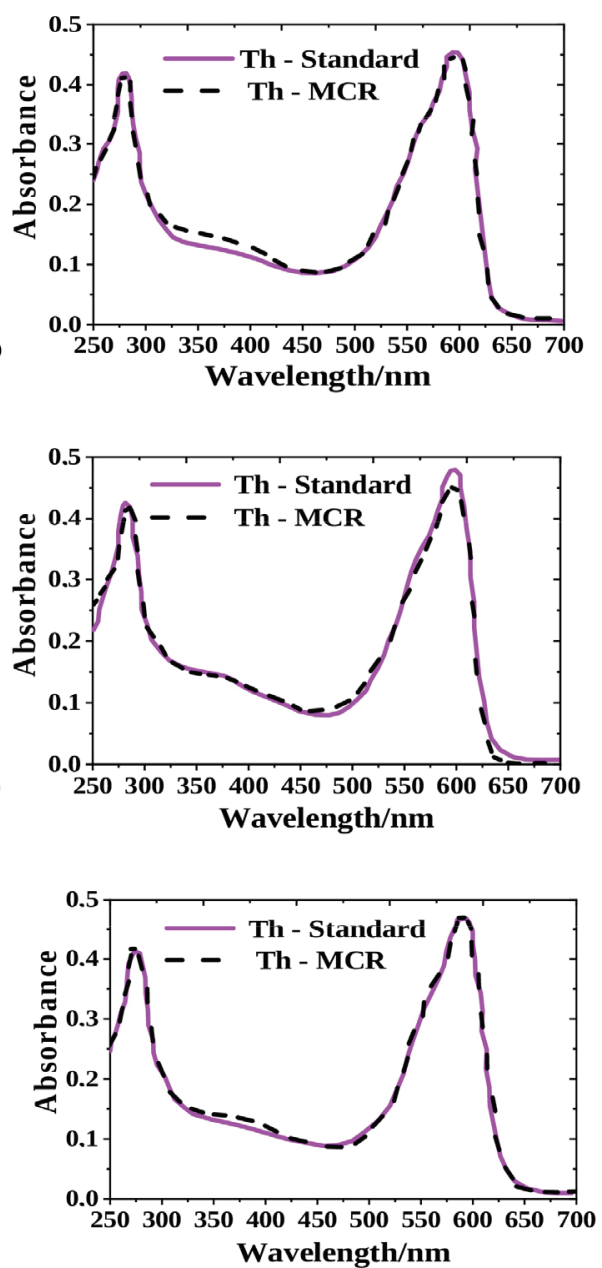

Figure 3. Results of the MCR-ALS spectral resolution procedure, showing comparison between the spectra of a pure dye standard (methylene blue (left) and thionine (right)) and the corresponding spectra obtained by application of the algorithm to the data for the experiments at pH (a) 2.0; (b) 4.0; (c) 6.0; and (d) 8.0.

in the solution, reaching values near $10 \mathrm{mg} \mathrm{L}^{-1}$. This suggested that the birnessite was consumed during the MB degradation process.

In aqueous solution at $\mathrm{pH} 4$ and in the absence of $\mathrm{MB}$, the amount of solubilized manganese was low $\left(1 \mathrm{mg} \mathrm{L}^{-1}\right)$, reflecting the solubility of the birnessite. In the presence of MB, the amount of manganese in the solution increased with increasing contact time, reaching values of around $4 \mathrm{mg} \mathrm{L}^{-1}$ (Figure 5).
At higher $\mathrm{pH}$ values (pH 6 and 8), the amount of $\mathrm{Mn}$ in the solution was low for all the experiments, remaining near the limit of quantification of the method, even in the presence of MB. A clear increase of manganese in the solution was only observed at $\mathrm{pH} 6$ and in the presence of $\mathrm{MB}$. At these higher $\mathrm{pH}$ values, the amount of manganese present in the solution was likely to be governed by the solubility of manganese hydroxides. ${ }^{7}$ 

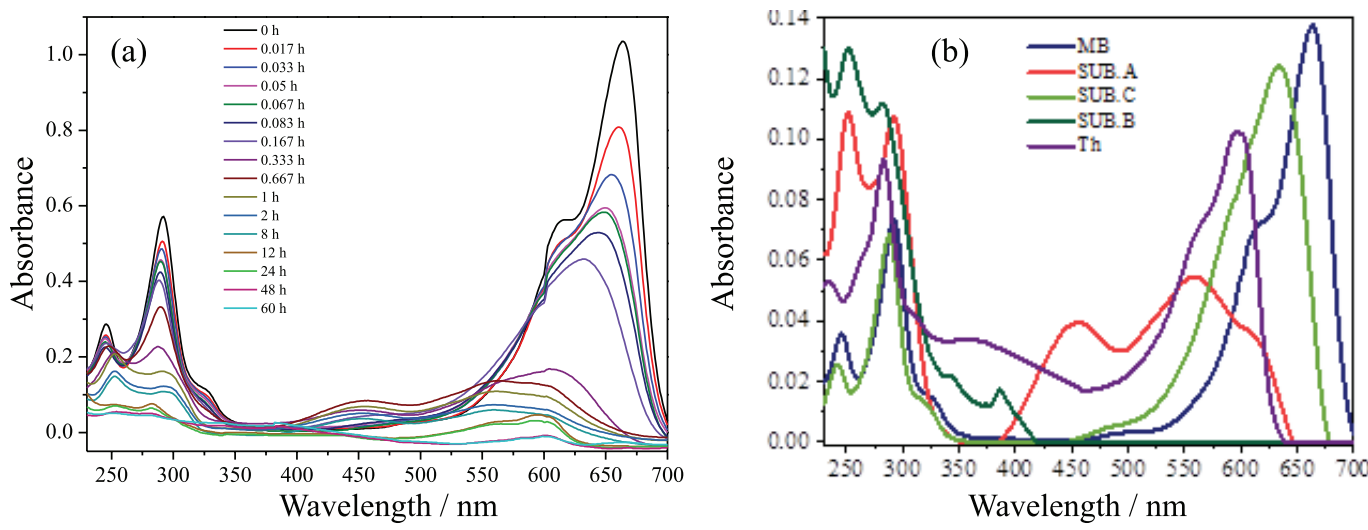

Figure 4. Spectral profiles obtained by (a) UV-Vis spectroscopy and (b) using the MCR-ALS, for treatment of the methylene blue solution (7 mg $\mathrm{L}^{-1}$ ) with $100 \mathrm{mg} \mathrm{L}^{-1}$ birnessite, at $\mathrm{pH} 4.0$ and $22{ }^{\circ} \mathrm{C}$, during a total contact time of $3600 \mathrm{~min}(60 \mathrm{~h})$.
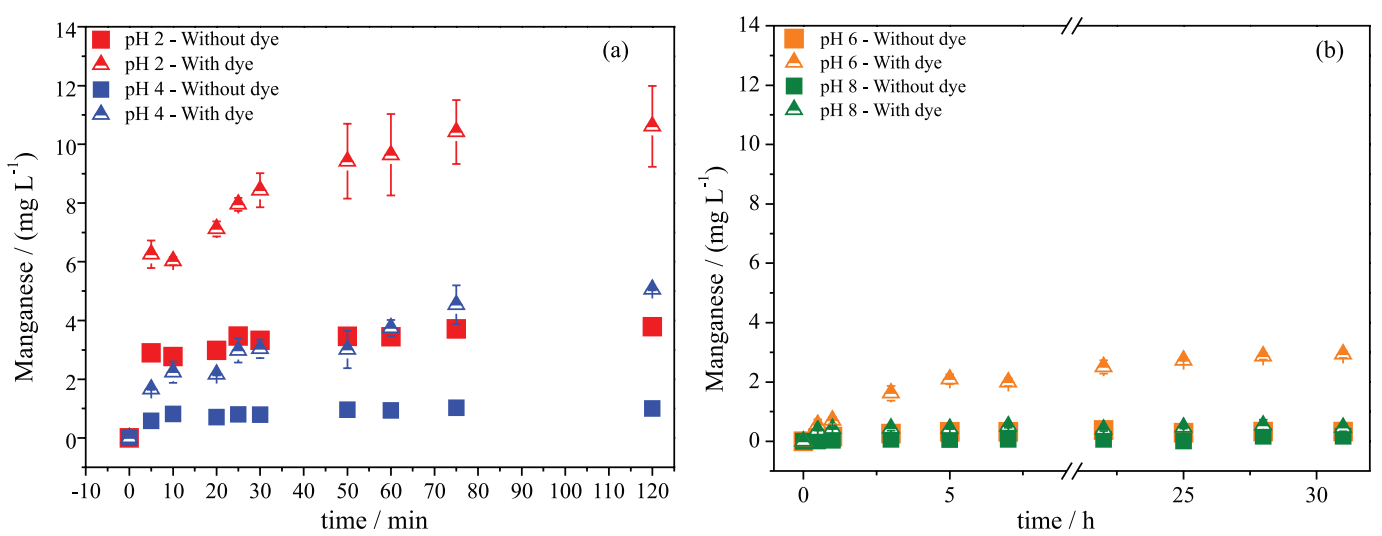

Figure 5. Concentrations of manganese present in solution after addition of $100 \mathrm{mg} \mathrm{L}^{-1}$ of birnessite to the different systems: (a) (ロ) pH 2.0 without the presence of the dye, $(\mathbf{A}) \mathrm{pH} 2.0$ with the presence of the dye, $(\mathbf{\square}) \mathrm{pH} 4.0$ without the presence of the dye, and $(\mathbf{A}) \mathrm{pH} 4.0$ with the presence of the dye;

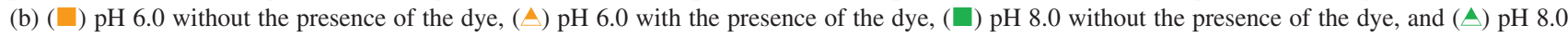
with the presence of the dye.

\section{Mechanism for direct electron transfer via radicals}

In order to understand the mechanism of degradation of MB by birnessite, the experiments described in "Removal of methylene blue from aqueous systems using birnessite" sub-section, but in the absence of the dye were repeated, with the addition of tert-butyl alcohol or $\mathrm{NaNO}_{2}$ to the MB solution. These experiments were performed under the conditions considered optimal (MB at $7 \mathrm{mg} \mathrm{L}^{-1}$ and birnessite loading of $100 \mathrm{mg} \mathrm{L}^{-1}$ ). It was decided to perform

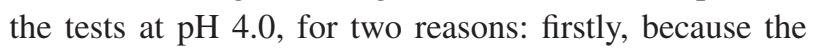
kinetics was slower, which allowed better monitoring of the process; secondly, because this $\mathrm{pH}$ value was more easily achieved, with lower reagent consumption. Monitoring of the degradation kinetics was performed by following the decay of the band at $664 \mathrm{~nm}$.

It can be clearly seen from Figure $6 a$ that the presence of tert-butyl alcohol did not affect the rate of dye oxidation. However, the presence of $\mathrm{NO}_{2}^{-}$inhibited $\mathrm{MB}$ removal by almost $80 \%$, probably due to competition between nitrite and the dye for oxidation.
Free radical species such as ${ }^{\circ} \mathrm{OH},{ }^{\circ} \mathrm{HOO}$, and ${ }^{\circ} \mathrm{O}_{2}{ }^{-}$may contribute to dye removal. ${ }^{39}$ Therefore, experiments were performed in the absence of oxygen, by bubbling $\mathrm{N}_{2}$ gas through the MB solution before and during the reaction. The results were similar to those obtained in the absence of $\mathrm{N}_{2}$ (Figure $6 \mathrm{~b}$ ), suggesting that oxidation of the MB molecules occurred preferentially on the surface or near the oxide, involving direct electron transfer, rather than reactions of radicals.

\section{Kinetic study}

Pseudo-first order and pseudo-second order kinetic models were applied to the data obtained during the removal of $\mathrm{MB}$ by the birnessite at the different $\mathrm{pH}$ values, considering the decay of the absorbances at the maximum absorbance wavelength of $664 \mathrm{~nm}$.

The parameters were obtained from nonlinear fitting performed using Origin 8.0 software $^{40}$ (Table S1, SI section). All the determination coefficient $\left(\mathrm{R}^{2}\right)$ values were close to 1 and the kinetic constant $(\mathrm{k})$ values indicated that 

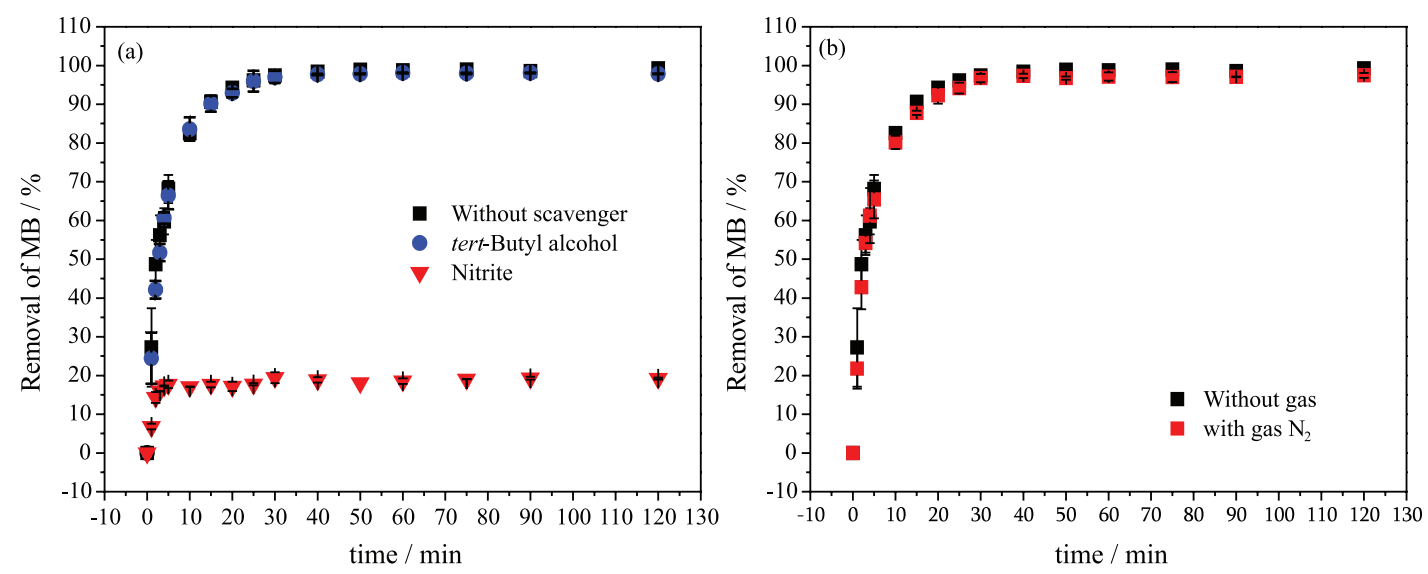

Figure 6. Removal percentage of $\mathrm{MB}\left(7 \mathrm{mg} \mathrm{L}^{-1}\right)$, at $\mathrm{pH} 4.0$ and $22{ }^{\circ} \mathrm{C}$, using $100 \mathrm{mg} \mathrm{L}^{-1}$ birnessite in the presence of (a) radical scavengers (tert-butyl alcohol and nitrite) and (b) nitrogen gas.

the rate of removal of $\mathrm{MB}$ was faster at lower $\mathrm{pH}(\mathrm{pH} 2.0$ and 4.0) (Figure S4, SI section).

For $\mathrm{pH} 2.0$ and 4.0, the pseudo-first order model provided the best fit to the experimental data, with lower dispersion of the residuals. For pH 6.0 and 8.0, the pseudosecond order model showed the best fit to the experimental data (Figure S4, SI section). These results provided further evidence that the processes of removal of MB were different at high and low $\mathrm{pH}$. In previous work, ${ }^{7,33}$ it was also shown that at optimal $\mathrm{pH}$, the pseudo-first order model provided the best description of the degradation of MB by birnessite.

\section{Thermodynamic study}

Experiments were performed at different temperatures $\left(16,22,30\right.$, and $\left.46^{\circ} \mathrm{C}\right)$, which were adjusted using a thermostatically-controlled water bath. Correlations between the temperatures and the rate constants $(\mathrm{k})$ were obtained by applying the pseudo-first order model to the data obtained at the different temperatures (Table S2, SI section). The parameters A (exponential factor) and $\mathrm{E}^{*}$ (activation energy) were calculated using the linear model of the Arrhenius equation, according to activated complex theory (equation 8):

$\ln \mathrm{k}=\ln \mathrm{A}-\frac{\mathrm{E}^{*}}{\mathrm{RT}}$

where $\mathrm{R}$ is the gas constant $\left(8.314 \mathrm{~J} \mathrm{~mol}^{-1} \mathrm{~K}^{-1}\right), \mathrm{T}$ is the temperature $(\mathrm{K})$, and $\mathrm{A}$ is the collision frequency (or preexponential factor). Plotting $\ln \mathrm{k}$ against $1 / \mathrm{T}$ gave a straight line, with $-\mathrm{E} / \mathrm{R}$ being the angular coefficient of the line and ln A being the linear coefficient (Figure S5, SI section). The calculated values of $\mathrm{E}^{*}$ and A were $32.66 \mathrm{~kJ} \mathrm{~mol}^{-1}$ and $2602.66 \mathrm{~s}^{-1}$, respectively.

Hence, the thermodynamic parameters including the Gibbs free energy of activation $\left(\Delta \mathrm{G}^{*}\right)$, the variation of the activation enthalpy $\left(\Delta \mathrm{H}^{*}\right)$, and the variation of the activation entropy $\left(\Delta \mathrm{S}^{*}\right)$ could be calculated using the Eyring equation (equation 9). ${ }^{41,42}$

$\ln \frac{\mathrm{k}}{\mathrm{T}}=\left(\ln \frac{\mathrm{k}_{\mathrm{b}}}{\mathrm{h}}-\frac{\Delta \mathrm{S}^{*}}{\mathrm{R}}\right)-\frac{\Delta \mathrm{H}^{*}}{\mathrm{RT}}$

where $\mathrm{k}$ is the kinetic constant obtained using the pseudofirst order model, $\mathrm{T}$ is the temperature $(\mathrm{K}), \mathrm{h}$ is Planck's constant $\left(6.6262 \times 10^{-34} \mathrm{~J} \mathrm{~s}\right)$, and $\mathrm{k}_{\mathrm{b}}$ is the Boltzmann constant $\left(1.3806 \times 10^{-23} \mathrm{~J} \mathrm{~K}^{-1}\right)$.

Therefore, from the equation obtained for the linear plot of $\ln (\mathrm{k} / \mathrm{T})$ against $1 / \mathrm{T}$, the angular coefficient provided the enthalpy value, while the intersection of the line gave the entropy value (Figure S6, SI section).

The thermodynamic parameters were calculated using equations 10-12 and are presented in Table 1.

$\mathrm{b}=\ln \frac{\mathrm{k}_{\mathrm{b}}}{\mathrm{h}}+\frac{\Delta \mathrm{S}^{*}}{\mathrm{R}}$

$\mathrm{a}=\frac{\Delta \mathrm{H}^{*}}{\mathrm{R}}$

$\Delta \mathrm{G}^{*}=-\mathrm{RT} \ln \left(\frac{\mathrm{kh}}{\mathrm{k}_{\mathrm{b}} \mathrm{T}}\right)$

where $\mathrm{a}$ and $\mathrm{b}$ are the angular and linear coefficients of the line equation, respectively.

Positive values of $\Delta \mathrm{G}^{*}$ indicate that the attainment of equilibrium between the reagent and the activated complex is not spontaneous. ${ }^{43} \mathrm{~A}$ negative value of the entropy change $\left(\Delta \mathrm{S}^{*}\right)$ indicates that the transition state possesses less structural freedom than the reactants. ${ }^{44}$

The energy variation is not related to the value or sign of the activation enthalpy $\left(\Delta \mathrm{H}^{*}\right)$, although in fact this value 
Table 1. Kinetic and thermodynamic parameters for the removal of $\mathrm{MB}\left(7 \mathrm{mg} \mathrm{L}^{-1}\right)$, at $\mathrm{pH} 4.0$, using $100 \mathrm{mg} \mathrm{L}^{-1}$ of birnessite

\begin{tabular}{lcccccc}
\hline \multirow{2}{*}{$\mathrm{E}^{*} /\left(\mathrm{kJ} \mathrm{mol}^{-1} \mathrm{~K}^{-1}\right)$} & $\Delta \mathrm{S}^{*} /\left(\mathrm{J} \mathrm{mol}^{-1} \mathrm{~K}^{-1}\right)$ & $\Delta \mathrm{H}^{*} /\left(\mathrm{kJ} \mathrm{mol}^{-1}\right)$ & \multicolumn{4}{c}{$\Delta \mathrm{G}^{*} /\left(\mathrm{kJ} \mathrm{mol}^{-1} \mathrm{~K}^{-1}\right)$} \\
\cline { 3 - 6 } & & 30.158 & $289 \mathrm{~K}$ & $296 \mathrm{~K}$ & $303 \mathrm{~K}$ & $319 \mathrm{~K}$ \\
\hline 26.108 & -16.741 & 54.345 & 55.473 & 57.353 & 59.232 \\
\hline
\end{tabular}

$E^{*}$ : activation energy; $\Delta S^{*}$ : activation entropy; $\Delta H^{*}$ : activation enthalpy; $\Delta \mathrm{G}^{*}$ : Gibbs free energy of activation.

is generally positive when the thermodynamic parameters are calculated based on linear relations, such as the Eyring equation. ${ }^{43}$ This is because the $\Delta \mathrm{H}^{*}$ and $\Delta \mathrm{S}^{*}$ values may be influenced by factors such as agitation, temperature, and $\mathrm{pH} .{ }^{45}$ Hence, at the equilibrium condition, thermodynamic compensation can generate statistical errors.

\section{Analysis of total organic carbon content}

Experiments were performed similarly to the removal and desorption assays described in "Removal of methylene blue from aqueous systems using birnessite" subsection. An initial analysis was made of the MB sample, before initiation of the degradation using birnessite $\left(\mathrm{TOC}_{\mathrm{INICIAL}}\right.$, where TOC is the total organic carbon), followed by analyses after 120 and 3600 min of reaction $\left(\mathrm{TOC}_{\mathrm{FINAL}(120 \mathrm{~min} / 3600 \mathrm{~min})}\right)$, as well as after the desorption procedure $\left(\mathrm{TOC}_{\text {DESORPTION(120 min / } 3600 \mathrm{~min})}\right)$.

The non-purgeable organic carbon (NPOC) method was used to quantify the total organic carbon contents of the samples after contact times of 120 and $3600 \mathrm{~min}$ (TOC FINAL, $^{120}$, TOC $_{\text {FINAL }}^{3600}$, TOC $_{\text {DESORPTION }}^{120}$, and TOC DESORPTION $^{3600}$ ) (Table S3, SI section).

Figure 7 shows a comparison of the TOC percentages at the start of the reaction (100\%) and after degradation of MB by birnessite during separate reactions performed for $120 \mathrm{~min}(45.89 \%)$ and $3600 \mathrm{~min}(18.68 \%)$. These results confirmed that the reaction continued after the $120 \mathrm{~min}$ period used initially, in agreement with the UV-Vis analyses showing that after $3600 \mathrm{~min}$, the absorbances were close to

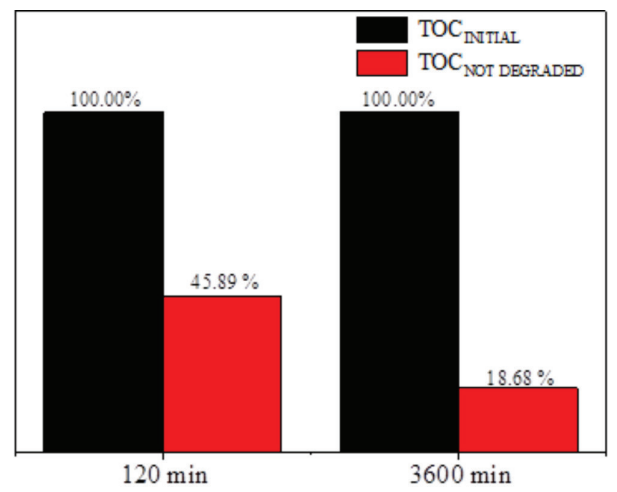

Figure 7. Organic carbon contents of the initial $\mathrm{MB}$ solution $\left(7 \mathrm{mg} \mathrm{L}^{-1}\right)$ and the solutions after the reactions performed at $\mathrm{pH} 4.0$ and $22^{\circ} \mathrm{C}$, using $100 \mathrm{mg} \mathrm{L}^{-1}$ birnessite, for 120 and $3600 \mathrm{~min}$. zero throughout the wavelength range, suggesting that the degradation process eventually led to the mineralization of MB.

\section{Conclusions}

The use of birnessite for the removal of the cationic dye $\mathrm{MB}$ resulted in faster degradation at lower $\mathrm{pH}$ values ( 2.0 and 4.0), with the removal following pseudo-first order kinetics. The best conditions for removal of the dye from aqueous solution were $\mathrm{pH} 4.0$, birnessite loading of $100 \mathrm{mg} \mathrm{L}^{-1}$, and temperature of $22{ }^{\circ} \mathrm{C}$. Analysis of TOC showed that the degradation proceeded towards mineralization of MB, with 60 and $80 \%$ elimination of the organic matter after 120 and $3600 \mathrm{~min}$, respectively, when $70 \mathrm{mg} \mathrm{L}^{-1} \mathrm{MB}$ was treated using $1.00 \mathrm{~g} \mathrm{~L}^{-1}$ birnessite, at $22{ }^{\circ} \mathrm{C}$ and $\mathrm{pH}$ 4.0. The results indicated that the degradation was probably due to the transfer of electrons, since the presence of tert-butyl alcohol (employed as a radical scavenger) did not alter the kinetics of the dye degradation reaction. The results obtained using the MCR-ALS method provided evidence of the formation of degradation byproducts and enabled the identification of thionine $\left(\lambda_{\max }=601 \mathrm{~nm}\right)$ as one of the byproducts of $N$-demethylation of the MB molecule during degradation of the dye in aqueous solution by birnessite.

\section{Supplementary Information}

Supplementary data (XRD, FTIR spectra, point of zero charge (PZC) and kinetic parameters and residues) are available free of charge at http://jbcs.sbq.org.br as PDF file.

\section{Acknowledgments}

The authors acknowledge the financial support of the Fundação de Amparo à Pesquisa do Estado de Minas Gerais (FAPEMIG) and the Conselho Nacional de Desenvolvimento Científico e Tecnológico (CNPq, process 409899/2016-0).

\section{Author Contributions}

Thaís de A. Cosendey was responsible for the conceptualization, data curation, formal analysis, 
investigation, software, validation, visualization, writing original draft, review and editing; Antônio A. Neves for the conceptualization, data curation, formal analysis, funding acquisition, investigation and project administration; Liany D. L. Miranda for the conceptualization, investigation, writing original draft, review and editing; Maria E. L. R. de Queiroz for the conceptualization and funding acquisition; André F. de Oliveira for the data curation, resources and software; Efraim L. Reis for the resources and software; Wesley L. Gabriel for the conceptualization, data curation, resources and software.

\section{References}

1. Brock, S. L.; Duan, N.; Tian, Z. R.; Giraldo, O.; Zhou, H.; Suib, S. L.; Chem. Mater. 1998, 10, 2619.

2. Feng, Q.; Kanoh, H.; Ooi, K.; J. Mater. Chem. A 1999, 9, 319.

3. Wei, W.; Cui, X.; Chen, W.; Ivey, D. G.; Chem. Soc. Rev. 2011, 40, 1697

4. Ahmed, K. A. M.; J. Taibah Univ. Sci. 2016, 10, 412.

5. Zhou, J.; Yu, L.; Sun, M.; Yang, S.; Ye, F.; He, J.; Hao, Z.; Ind. Eng. Chem. Res. 2013, 52, 9586.

6. Frias, D.; Nousir, S.; Barrio, I.; Montes, M.; López, T.; Centeno, M. A.; Odriozola, J. A.; Mater. Charact. 2007, 58, 776.

7. Zaied, M.; Peulon, S.; Bellakhal, N.; Desmazieres, B.; Chausse, A.; Appl. Catal., B 2011, 101, 441.

8. Zaied, M.; Chutet, E.; Peulon, S.; Bellakhal, N.; Desmazières, B.; Dachraoui, M.; Chaussé, A.; Appl. Catal., B 2011, 107, 42.

9. Pang, J.; Fu, F.; Ding, Z.; Lu, J.; Li, N.; Tang, B.; J. Taiwan Inst. Chem. Eng. 2017, 77, 168.

10. Qin, M.; Zhao, H.; Yang, W.; Zhou, Y.; Li, F.; RSC Adv. 2016, 6, 23905.

11. Chen, Y.; Lu, X.; Liu, L.; Wan, D.; Chen, H.; Zhou, D.; Sharma, V. K.; Chemosphere 2018, 194, 588.

12. Lin, K.; Peng, Y.; Huang, X.; Ding, J.; Environ. Sci. Pollut. Res. 2013, 20, 1461.

13. Varghese, S. P.; Babu, A. T.; Babu, B.; Antony, R.; J. Water Process Eng. 2017, 19, 1.

14. Forgacs, E.; Cserhati, T.; Oros, G.; Environ. Int. 2004, $30,953$.

15. Dang, T. D.; Banerjee, A. N.; Tran, Q. T.; Roy, S.; J. Phys. Chem. Solids 2016, 98, 50.

16. Wu, S.; Wallace, S.; Brix, H.; Kuschk, P.; Kirui, W. K.; Masi, F.; Dong, R.; Environ. Pollut. 2015, 201, 107.

17. Holler, F. J.; Skoog, D. A.; Crouch, S. R.; Princípios de Análise Instrumental, vol. 1, $6^{\text {th }}$ ed.; Bookman: Porto Alegre, Brazil, 2009.

18. Garrido, M.; Rius, F. X.; Larrechi, M. S.; Anal. Bioanal. Chem. 2008, 390, 2059.

19. Gonçalves, R. P.; Março, P. H.; Valderrama, P.; Quim. Nova 2015, 38, 864 .
20. Khataee, A.; Gohari, S.; Fathinia, M.; J. Taiwan Inst. Chem. Eng. 2016, 65, 172.

21. Terra, L. R.; Catrinck, M. N.; Teófilo, R. F.; Chemom. Intell. Lab. Syst. 2017, 167, 132.

22. Liu, L.; Luo, Y.; Tan, W.; Zhang, Y.; Liu, F.; Qiu, G.; J. Colloid Interface Sci. 2016, 482, 183.

23. Março, P. H.; Valderrama, P.; Alexandrino, G. L.; Poppi, R. J.; Tauler, R.; Quim. Nova 2014, 37, 1525.

24. MathWorks; MATLAB, R2018a; MathWorks, United States, 2018.

25. https://mcrals.wordpress.com/download/mcr-als-2-0-toolbox, accessed in January 2020.

26. Figueira, B. A. M.; Scheller, T.; Angélica, R. S.; Cerâmica 2008, 54,184

27. Wang, X.; Mei, L.; Xing, X.; Liao, L.; Lv, G.; Li, Z.; Wu, L.; Appl. Catal., B 2014, 160, 211.

28. Zhang, W.; Yang, Z.; Wang, X.; Zhang, Y.; Wen, X.; Yang, S.; J. Phys. Chem. Solids 2015, 83, 40.

29. Boumaiza, H.; Coustel, R.; Medjahdi, G.; Ruby, C.; Bergaoui, L.; J. Solid State Chem. 2017, 248, 18.

30. Victor, R. P. D.; Fontes, L. L. M.; Neves, A. A.; de Queiroz, M. E. L. R.; de Oliveira, A. F.; Miranda, L. D. L.; J. Braz. Chem. Soc. 2019, 30, 1769.

31. Ling, F. T.; Post, J. E.; Heaney, P. J.; Kubicki, J. D.; Santelli, C. M.; Spectrochim. Acta, Part A 2017, 178, 32.

32. Ghodbane, O.; Pascal, J. L.; Favier, F.; ACS Appl. Mater. Interfaces 2009, 1, 1130.

33. Zhu, M. X.; Wang, Z.; Xu, S. H.; Li, T.; J. Hazard. Mater. 2010 , 181, 57.

34. Kuan, W. H.; Chan, Y. C.; J. Hazard. Mater. 2012, 239, 152.

35. Lindsay, W. L.; Chemical Equilibria in Soils, vol. 1, $1^{\text {st }}$ ed.; John Wiley and Sons Ltd., Colorado State University: Fort Collins, USA, 1979.

36. Azzouz, T.; Tauler, R.; Talanta 2008, 74, 1201.

37. Jaumot, J.; Gargallo, R.; De Juan, A.; Tauler, R.; Chemom. Intell. Lab. Syst. 2005, 76, 101.

38. Juan, A.; Jaumot, J.; Tauler, R.; Anal. Methods 2014, 6, 4964.

39. Zhang, W.; Yang, Z.; Wang, X.; Zhang, Y.; Wen, X.; Yang, S.; Catal. Commun. 2006, 7, 408.

40. Origin Pro, 95E; OriginLab, Northampton, USA, 2018.

41. Silva, V. H.; Aquilanti, V.; de Oliveira, H. C.; Mundim, K. C.; Chem. Phys. Lett. 2013, 590, 201.

42. Rodrigues, J. S.; do Valle, C. P.; Guerra, P. D. A. G. P.; Rios, M. A. S.; Malveira, J. Q.; Ricardo, N. M.; Fuel Process. Technol. 2017, 161, 95 .

43. Ibarz, R.; Garvín, A.; Ibarz, A.; Food Res. Int. 2017, 99, 348.

44. Mercali, G. D.; Jaeschke, D. P.; Tessaro, I. C.; Marczak, L. D. F.; Food Chem. 2013, 136, 853.

45. Garvín, A.; Ibarz, R.; Ibarz, A.; Food Res. Int. 2017, 96, 132.

Submitted: October 8, 2019

Published onliune: February 14, 2020 